\title{
AVALIAÇÃo E QUANTIFICAÇÃO DAS FRAÇÕES SILTE, AREIA E ARGILA POR MEIO DE SUAS RESPECTIVAS REFLECTÂNCIAS ${ }^{(1)}$
}

\author{
Everson Cezar $^{(2)}$, Marcos Rafael Nanni ${ }^{(3)}$, Marcelo Luiz Chicati ${ }^{(4)}$, Ivan Granemann de \\ Souza Junior ${ }^{(5)}$ \& Antonio Carlos Saraiva da Costa ${ }^{(6)}$
}

\begin{abstract}
RESUMO
A utilização de testes de rotina para determinação de atributos físicos e químicos do solo vem sendo adotada há diversos anos. No entanto, devido a problemas de ordem econômica e ambiental, surge a necessidade do desenvolvimento de novos métodos de avaliação. Nesse contexto, insere-se a espectroscopia de reflectância difusa como ferramenta promissora e rápida, capaz de ajudar na determinação desses atributos. Os objetivos deste trabalho foram estudar o comportamento espectral das frações silte, areia e argila e avaliar a possibilidade de quantificação desses atributos a partir de modelos de regressão individuais gerados para cada elemento. Para geração dos modelos, foram utilizadas frações individuais de silte, areia e argila provenientes de duas áreas formadas por materiais distintos. A validação dos modelos foi feita utilizando o fator de reflectância de amostras de solo no estado natural, advindas de uma área no município de Lobato - PR. Os resultados mostraram que foi possível estimar a percentagem de areia nas amostras de solo de Lobato de maneira satisfatória quando utilizados os modelos individuais da usina Cooperval, não sendo obtido o mesmo quando da utilização dos modelos individuais ajustados para a Fazenda Experimental de Iguatemi. Com relação às frações silte e argila, não foi possível estimá-las satisfatoriamente nas amostras de solo de Lobato quando utilizados os modelos individuais. Conclui-se que, embora os resultados não tenham atingido o
\end{abstract}

\footnotetext{
(1) Parte da tese de Doutorado do primeiro autor. Recebido para publicação em 25 de novembro de 2011 e aprovado em 14 de junho de 2012.

(2) Engo. Agro, Doutorando em Agronomia, Universidade Estadual de Maringá - UEM, Av. Colombo, 5790, CEP 87020-900 Maringá (PR). E-mail: eversoncezar@yahoo.com.br

(3) Prof. Dr., PGA, UEM, Av. Colombo, 5790, CEP 87020-900 Maringá (PR). E-mail: mrnanni@uem.br

(4) Prof. Dr., DEC, UEM, Av. Colombo, 5790, CEP 87020-900 Maringá (PR). E-mail: mlchicati@yahoo.com.br

(5) Dr., Lab. Química e Mineralogia de Solos, UEM, Av. Colombo, 5790, CEP 87020-900 Maringá (PR). E-mail: ivangsjunior@gmail.com

${ }^{(6)}$ Prof. Dr., PGA, UEM, Av. Colombo, 5790, CEP 87020-900 Maringá (PR). E-mail: acscosta@uem.br
} 


\begin{abstract}
patamar ideal, a espectrorradiometria difusa mostrou ser uma ferramenta promissora na estimativa dos atributos físicos do solo, podendo num futuro próximo auxiliar ou mesmo substituir os métodos analíticos de laboratório, reduzindo o tempo e o custo das análises.
\end{abstract}

Termos de indexação: raios X, técnica analítica, espectrorradiômetro, solos.

\author{
SUMMARY: EVALUATION AND QUANTIFICATION OF THE FRACTIONS \\ SILT, SAND AND CLAY BY DIFFUSE REFLECTANCE \\ SPECTROSCOPY
}

\begin{abstract}
Routine tests to determine physical and chemical soil properties have been used for several years. However, due to economic and environmental problems, new assessment methods must be developed. In this context, diffuse reflectance spectroscopy is a promising and quick tool in the determination of these properties. The objective of this work was to study the spectral behavior of the silt, sand and clay fractions and evaluate the possibility of quantifying these properties with regression models generated for each individual element. To develop the models, individual silt, sand and clay fractions from two areas formed by different materials were used. The models were validated using the reflectance factor of soil samples in their natural state collected in the municipality of Lobato, Paraná. The results showed that it was possible to satisfactorily estimate the percentage of sand in soil samples from Lobato by individual models of the Cooperval production plant, unlike in the case of individual models adjusted for the Experimental Farm of Iguatemi. It was not possible to estimate the silt and clay fraction in the Lobato soil samples satisfactorily by the individual models. It was therefore concluded that although the results had not reached the ideal level, diffuse spectroradiometry proved to be a promising tool for the estimation of soil physical properties; in the near future this technique may support or even replace the analytical laboratory methods, reducing the time and cost spent on the analyses.
\end{abstract}

Index terms: X-ray, analysis technique, spectroradiometer, soils.

\section{INTRODUÇÃO}

Teste de rotina para amostras de solo e de perfil utilizam análises químicas, físicas e mineralógicas como técnicas bases para determinação da composição do solo. Esses métodos de diagnóstico são considerados confiáveis devido à base de pesquisa envolvida e ao grande número de testes que têm sido conduzidos desde seu estabelecimento (Nanni \& Demattê, 2006).

No entanto, apesar de eficiente, a utilização dessas técnicas é demasiadamente cara e demorada. No caso dos atributos físicos, por exemplo, a fração argila, assim como as demais, é determinada por processo de sedimentação, usando as leituras em hidrômetro. Esse método é lento e consome espaço, além de ser trabalhoso (Sorensen \& Dalsgaard, 2005).

De acordo com Shepherd \& Walsh (2002) e Nanni \& Demattê (2006), o desenvolvimento de métodos mais rápidos e viáveis para quantificar as propriedades do solo, de modo geral, é necessário. A espectroscopia de reflectância difusa (DRS) é uma técnica promissora, não destrutiva, que pode cumprir esses requisitos (Lee et al., 2010). Muitos pesquisadores têm estimado com sucesso atributos físicos e químicos do solo utilizando DRS (Viscarra Rossel et al., 2009; Volkan Bilgili et al., 2010; Sousa Júnior et al., 2011, entre outros).
No entanto, para que essa técnica venha a substituir as técnicas analíticas atuais de forma efetiva, é necessário o desenvolvimento de estudos mais detalhados acerca do comportamento espectral individualizado de cada atributo do solo, fato esse que não tem ocorrido, uma vez que a maioria dos trabalhos utiliza amostras de solo no estado natural (sem fracionamento). Espera-se que, a partir da energia refletida de cada atributo individual, possam ser obtidos modelos de estimação mais robustos do que os desenvolvidos até o momento.

Este trabalho teve como objetivos estudar o comportamento espectral das frações silte, areia e argila de dois Latossolos Vermelhos originários de diferentes materiais e avaliar a possibilidade de quantificação desses atributos em amostras desconhecidas, utilizando modelos de regressão individuais gerados para cada elemento.

\section{MATERIAL E MÉTODOS}

Para que o trabalho pudesse ser realizado, foram escolhidas três áreas, formadas por diferentes materiais de origem, com o intuito de obter-se a 
máxima variação nos atributos físicos, químicos e mineralógicos entre as amostras de solo. Suas localizações são demarcadas pelas coordenadas geográficas: $23^{\circ} 40^{\prime} 30^{\prime \prime}$ de latitude sul e $51^{\circ} 45^{\prime} 40^{\prime \prime}$ de longitude oeste (Usina Cooperval), $23^{\circ} 21^{\prime} 36.83^{\prime \prime}$ de latitude sul e $52^{\circ} 04^{\prime} 27.63$ " de longitude oeste (Fazenda Experimental de Iguatemi - FEI) e $22^{\circ} 57^{\prime} 19.34^{\prime \prime}$ a $22^{\circ} 53^{\prime} 32.87^{\prime \prime}$ de latitude sul e $52^{\circ} 3^{\prime} 12.30^{\prime \prime}$ a $52^{\circ} 0^{\prime}$ $15.08^{\prime \prime}$ de longitude oeste (município de Lobato - PR).

As amostragens de solo foram realizadas com trado holandês nas profundidades de 0 - 0,2 e 0,8 - 1,0 m, para que se pudesse avaliar os atributos físicos, químicos e mineralógicos dos horizontes superficiais e subsuperficiais. A classificação de solos baseada em dados de análise física e química, como descrito por Embrapa (2006), assim como a avaliação de campo, indicou a presença de Latossolo Vermelho na área da usina Cooperval (derivado de basalto) e da FEI (derivado de arenito do grupo Caiuá), ao passo que na área de Lobato foram encontrados Latossolo Vermelho, Nitossolo Vermelho, Argissolo Vermelho, Cambissolo Háplico e Neossolo Quartzarênico (derivados de arenito do grupo Caiuá recobrindo o basalto formação Serra Geral).

Após a coleta, as amostras obtidas na usina Cooperval e na Fazenda Experimental de Iguatemi foram enviadas ao laboratório de análises mineralógicas da Universidade Estadual de Maringá (UEM) para serem submetidas ao processo de fracionamento e obtenção das frações silte, areia e argila para ambos os horizontes: Ap e Bw. Durante este processo, foi aplicada combinação de tratamento físico-químico sobre as amostras para melhorar a eficiência de dispersão.

$\mathrm{O}$ tratamento químico foi realizado por meio da adição de hipoclorito de sódio $12,5 \%$ (remoção da matéria orgânica) e $\mathrm{NaOH} 1 \mathrm{~mol} \mathrm{~L}^{-1}$ (dispersão), enquanto o tratamento físico foi realizado por meio de agitação rápida. A fração areia foi separada por tamisamento (utilizando peneira com malha de 0,053 mm de diâmetro), e a fração argila, por sifonamento após sedimentação da fração silte, conforme lei de Stokes.

Após separação, as amostras de argila foram floculadas com $\mathrm{MgCl}_{2} 1 \mathrm{~mol} \mathrm{~L}^{-1}$, e o excesso de sais foi removido por meio de lavagens sucessivas. Posteriormente, essa fração em conjunto com a fração silte e areia foram secas em estufa a $50{ }^{\circ} \mathrm{C}$, por $48 \mathrm{~h}$, e passadas em gral de porcelana, para uniformização do tamanho das partículas.

Essas amostras foram divididas em subamostras, as quais foram encaminhadas ao Complexo de Centrais de Apoio à Pesquisa (COMCAP) da UEM para serem analisadas por difração de raios-X (DRX) na forma de pó, empregando-se um equipamento Shimadzu XRD 6000. Os difratogramas de raios-X foram obtidos utilizando radiação $\mathrm{CoK} \alpha$ em uma varredura escalonada de $0,02^{\circ} 2 \theta$ por min, na faixa de 10 a $65^{0} 2 \theta$. Após a leitura, foi gerado um arquivo txt, contendo todos os resultados. Esses dados foram inseridos no software ConvX - XRD, para conversão em formato DiffracPlus RAW. A interpretação foi efetuada por comparação com padrões contidos no PDF 02 (ICDD, 1996), em software X'Pert HighScore Plus.

Paralelamente, as amostras coletadas em Lobato foram encaminhadas ao laboratório de solos da UEM, onde passaram por processo de secagem ao ar e peneiramento em malha de $2 \mathrm{~mm}$, para obtenção da terra fina seca ao ar (TFSA). Em seguida, as amostras de TFSA foram divididas em subamostras e submetidas a avaliações laboratoriais preconizadas por Embrapa (1997), para determinação das frações silte, areia e argila, assim como do carbono orgânico.

Em ambiente devidamente preparado, o restante das amostras das frações silte, areia e argila, assim como das amostras de Lobato (TFSA), foi submetido à avaliação em espectrorradiômetro FieldSpec $3 \mathrm{jr}$, o qual recobre a faixa espectral de 350 a $2.500 \mathrm{~nm}$. O equipamento foi programado para realizar 50 leituras/ amostra, resultando em uma curva espectral média. A geometria de aquisição dos dados utilizou-se de placapadrão branca com $100 \%$ de reflectância.

O leitor de fibra óptica foi colocado em posição vertical de $8 \mathrm{~cm}$ de distância da plataforma de apoio para amostras. A área de leitura gerada foi de aproximadamente $2 \mathrm{~cm}^{2}$. A fonte de iluminação utilizada foi uma lâmpada de $650 \mathrm{~W}$, com feixe não colimado para o plano visado, posicionada a $35 \mathrm{~cm}$ da plataforma e com ângulo de $30^{\circ}$ em relação ao plano horizontal. A relação entre a energia refletida pelo alvo e a energia refletida pela placa de referência gerou o fator de reflectância bidirecional, o qual foi utilizado no estudo dos atributos.

Como todos os ensaios foram realizados em laboratório em condições controladas, utilizou-se o delineamento inteiramente casualizado (DIC), com quatro repetições, para estudar os efeitos de 11 porções de silte, areia e argila (Tratamentos): $0,1,2,3,4,5$, $6,7,8,9$ e $10 \mathrm{~g}$ sobre o fator de reflectância. Essas porções simularam os teores de cada elemento de $0 \mathrm{a}$ $100 \%$ no solo.

Os tratamentos foram avaliados por meio de análise de regressão desenvolvida no Statistical Analysis System (SAS, 2001). Nos modelos lineares gerados, todos os coeficientes da regressão foram testados por meio do teste t a $1 \%$. Nos modelos não lineares, os coeficientes foram testados pelo intervalo de confiança, a $5 \%$. Para validação desses modelos, foram utilizados os dados de fator de reflectância das amostras de Lobato, os quais não participaram da geração deles, assim como o teor de silte, areia e argila de cada ponto amostrado nessa localidade. Dessa forma, foram confrontados os resultados obtidos pelos modelos com os de laboratório, com o intuito de avaliar se as médias observadas e estimadas apresentavam diferenças. Para isso, utilizou-se o procedimento PROC "t teste" do SAS a $5 \%$, o qual é capaz de testar as médias, duas a duas. 
Em razão da dificuldade de se concentrar um determinado elemento como argila, por exemplo, até $100 \%$, optou-se por trabalhar com diluições, em que foi sempre mantido o mesmo peso em todos os tratamentos, porém variando-se a quantidade de cada elemento. Para isso, os elementos foram diluídos em Borita, o qual não influencia o comportamento espectral dos elementos. Assim, esse material funcionou primeiro como testemunha (porção 0) e depois como enchimento (outras porções), tendo somente função de completar o peso fixado para cada tratamento.

Antes de proceder-se à análise estatística, foram realizadas avaliações visuais das curvas espectrais, assim como revisões bibliográficas, a fim de definir o melhor local ou intervalo de comprimento de onda que poderia representar da melhor maneira possível os elementos pesquisados.

\section{RESULTADOS E DISCUSSÃO}

\section{Fração argila}

Os resultados de equações de regressão obtidos para o fator de reflectância dos horizontes $\mathrm{Ap}$ e $\mathrm{Bw}$, utilizando a fração argila como variável independente, são apresentados no quadro 1 . Foi utilizada a faixa espectral de 1.100 a $1.870 \mathrm{~nm}$ para as amostras da FEI e de 1.050 a $1.870 \mathrm{~nm}$ para as amostras da usina Cooperval.
O aumento na quantidade de argila do horizonte Ap fez com que seu fator de reflectância apresentasse comportamento espectral linear decrescente e altamente significativo $\left(R^{2}=0,99 * *\right)$ para a classe de solo encontrada nas duas localidades. Os resultados obtidos estão relacionados com o aumento na quantidade de óxidos de $\mathrm{Fe}$, sendo representados por hematita, goethita e maghemita/magnetita, os quais se encontram como parte do grão de argila ou na forma de agentes cimentantes, concordando assim com o preconizado por Rencz (1999).

Da mesma forma, para as amostras de subsuperficie, o aumento na quantidade de argila provocou queda do albedo no intervalo médio de comprimento de onda pesquisado. A presença de comportamento linear decrescente e significativo encontra-se mais uma vez relacionada com o aumento na quantidade de óxidos de Fe no horizonte Bw, uma vez que os Latossolos Vermelhos são solos bem intemperizados e que apresentam teores de óxidos de Fe variando de baixa a elevada (Embrapa, 2006). Essas constatações feitas para a fração argila dos horizontes Ap e Bw são corroboradas por meio dos difratogramas de raios-X (Figura 1).

Observou-se que a fração argila do horizonte Ap dos dois solos apresentou dominância de caulinita, seguida de hematita, gibbsita, goethita e maghemita/ magnetita. Contudo, estes três últimos minerais (goethita e maghemita/magnetita) não foram detectados na amostra proveniente da FEI. No entanto, esse resultado não assegura com $100 \%$ de certeza a não existência desses minerais de $\mathrm{Fe}$ na fração argila.

Quadro 1. Equações de regressão obtidas a partir do fator de reflectância das frações argila, areia e silte dos horizontes Ap e Bw, fracionadas das amostras de solo da FEI e da usina Cooperval

\begin{tabular}{|c|c|c|}
\hline Amostra & Equação de regressão & $\mathbf{R}^{2}$ \\
\hline \multicolumn{3}{|c|}{ Fração Argila } \\
\hline Usina Cooperval_HAp & $\hat{\mathbf{y}}=0,597690-0,043269 x$ & $0,99 * *$ \\
\hline FEI_HAp & $\hat{\mathbf{y}}=0,618986-0,043430 x$ & $0,99^{* *}$ \\
\hline Usina Cooperval_HBw & $\hat{\mathbf{y}}=0,608210-0,044594 x$ & $0,99^{* *}$ \\
\hline FEI_HBw & $\hat{\mathbf{y}}=0,612811-0,039414 x$ & $0,99 * *$ \\
\hline \multicolumn{3}{|c|}{ Fração Areia } \\
\hline Usina Cooperval_HAp & $\hat{\mathbf{y}}=0,665510-0,057598 x$ & $0,99 * *$ \\
\hline FEI_HAp & $\hat{\mathbf{y}}=0,650610-0,010121 x$ & $0,89^{* *}$ \\
\hline Usina Cooperval_HBw & $\hat{\mathbf{y}}=0,658580-0,057078 \mathrm{x}$ & $0,99^{* *}$ \\
\hline FEI_HBw & $\hat{\mathbf{y}}=0,648418-0,005394 x$ & $0,85^{* *}$ \\
\hline \multicolumn{3}{|c|}{ Fração Silte } \\
\hline Usina Cooperval_HAp & $\hat{\mathbf{y}}=1 / 1,6265+0,4294 x$ & $0,99 * *$ \\
\hline FEI_HAp & $\hat{\mathbf{y}}=1 / 1,6297+0,2120 x$ & $0,99 * *$ \\
\hline Usina Cooperval_HBw & $\hat{\mathbf{y}}=1 / 1,5973+0,3080 x$ & $0,99 * *$ \\
\hline FEI_HBw & $\hat{\mathbf{y}}=1 / 1,6594+0,2088 x$ & $0,99 * *$ \\
\hline
\end{tabular}

**Significativo a $1 \%$; HAp: horizonte Ap; HBw: horizonte Bw. 
Segundo Silva et al. (2010), teores de minerais abaixo de $5 \%$ numa amostra dificilmente serão detectados pela técnica de raios-X. Portanto, nos dois casos, o aumento na percentagem de argila certamente levou ao aumento na quantidade de óxidos de $\mathrm{Fe}$, os quais influenciaram o comportamento espectral, como relatado por Demattê \& Garcia (1999).

Com relação ao horizonte $\mathrm{Bw}$, a caulinita foi o mineral dominante em todas as amostras de argila pesquisadas, seguida da hematita. Minerais como goethita, gibbsita e maghemita/magnetita. No entanto, o quartzo foi detectado apenas na amostra de argila pertencente à usina Cooperval. Esse fato ocorreu provavelmente em razão do intenso intemperismo físico e químico sofrido pelo solo, o qual levou à diminuição no tamanho do mineral, sendo este similar ao tamanho da partícula de argila $(<0,002 \mathrm{~mm})$, ou em razão da contaminação da amostra durante o fracionamento em laboratório.

Novamente, a fração argila da FEI não apresentou o mineral maghemita/magnetita, possivelmente devido à sua pequena quantidade no solo, estando abaixo de 5 $\%$, não sendo assim detectada pelos raios-X. No entanto, embora não se observe esse mineral, o comportamento espectral da fração argila proveniente da FEI é semelhante ao da usina Cooperval, sugerindo que os óxidos de Fe presentes foram responsáveis pela redução da resposta espectral em todo o espectro pesquisado.

\section{Fração areia}

O intervalo de comprimento de onda médio utilizado para avaliação da resposta espectral da fração areia foi de 1.000 a $1.880 \mathrm{~nm}$ para amostras da usina Cooperval e de 1.000 a $1.935 \mathrm{~nm}$ para amostras da FEI, considerando os horizontes de superfície e de subsuperficie. As equações de regressão obtidas para os experimentos são apresentadas no quadro 1.

A fração areia dos dois horizontes apresentou comportamento espectral linear decrescente e altamente significativo $\left(\mathrm{R}^{2}=0,85^{* *}\right.$ a $\left.0,99 * *\right)$ nas regiões espectrais de estudo à medida que ela foi adicionada a Borita. Comportamento linear, porém crescente, era esperado para esse atributo, no entanto isso não ocorreu. A explicação encontra-se vinculada ao material utilizado como testemunha, o qual possui albedo extremamente elevado quando comparado à areia. Dessa forma, acredita-se que, se o teor de areia aumentasse no solo no estado natural, seu fator de reflectância teria comportamento linear, porém crescente, concordando com o descrito por Nanni (2000).

No entanto, um fator interessante observado foi a capacidade dos óxidos de Fe de absorver a energia eletromagnética. Quando se compararam os dois experimentos, observou-se que, para a quantidade de $10 \mathrm{~g}$ (100\% de areia), o fator de reflectância para a areia da usina Cooperval em ambos os horizontes atingiu valor próximo de 0,1 . Por outro lado, quando se observou o fator de reflectância da areia advinda da amostra de solo da FEI, constatou-se que ele apresentou valor cinco vezes maior, ficando entre 0,5 e 0,59. Esse fato deve-se à presença da hematita recobrindo o grão de areia, assim como ao acúmulo de magnetita/maghemita nessa fração, as quais são capazes de reduzir o albedo não apenas em
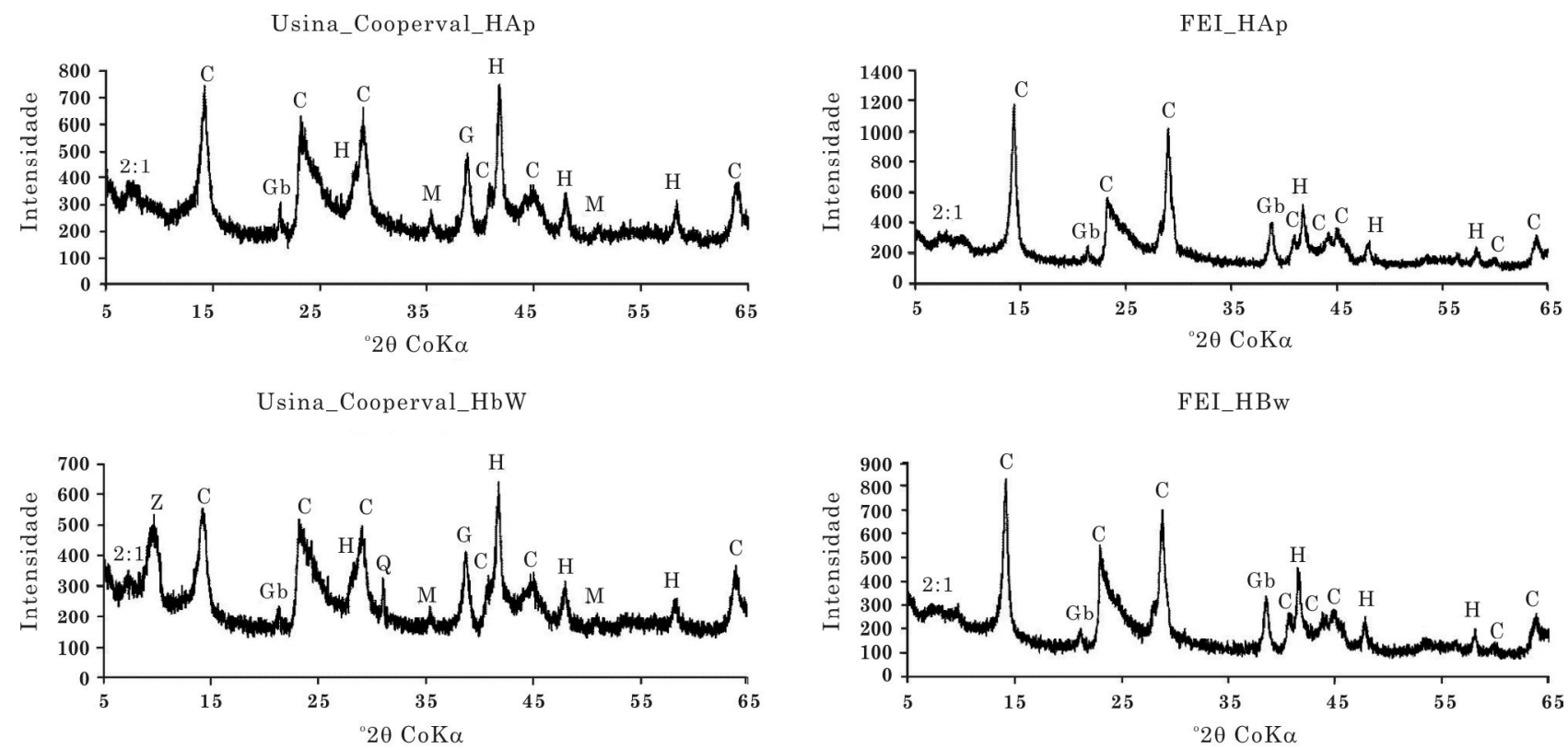

Figura 1. Difratogramas de raios-X (montagem em pó) da fração argila pertencente aos horizontes Ap (HAp) e Bw (HBw). C - caulinita; H - hematita; M - maghemita/magnetita; Gb - gibbsita; G - goethita; $Q$ - quartzo. 
determinados pontos da curva espectral, mas também em toda a curva, concordando com o descrito por Demattê \& Garcia (1999).

Essas observações concordam com os resultados de raios-X (Figura 2), onde é mostrado que o solo derivado de basalto apresenta quantidade elevada de óxidos de Fe, especificamente hematita e maghemita/ magnetita, enquanto o solo derivado de arenito do grupo Caiuá apresenta quantidade elevada de quartzo, com pouca ou nenhuma presença de óxidos de Fe.

Como mencionado, foi possível constatar que a fração areia do solo da usina Cooperval, em ambos os horizontes, apresentou elevada quantidade de hematita e maghemita/magnetita. Embora tenha sido realizado tratamento físico-químico para dispersão das partículas, observou-se que a hematita não pode ser totalmente removida da superfície do grão de areia, formando uma espécie de filme avermelhado. Da mesma forma, o mineral maghemita/magnetita, por ser mais resistente ao intemperismo, encontra-se como parte da fração. Além desses, outros minerais estão presentes, porém em menores quantidades: quartzo, anatásio e rutilo.

Com relação à areia da FEI, observa-se que o quartzo foi o mineral dominante. No entanto, as leituras espectrais realizadas em cada tratamento mostraram a presença de bandas de absorção próximas de $900 \mathrm{~nm}$, quando atingida a quantidade de $8 \mathrm{~g} \mathrm{(80 \%} \mathrm{de} \mathrm{areia),}$ para o horizonte Ap, e $5 \mathrm{~g}$ (50\% de areia), para o horizonte $\mathrm{Bw}$, típica da presença óxido de Fe, mais precisamente hematita, os quais se encontram na forma de agente cimentante ou de filme (película). Além disso, a utilização de ímã mostrou haver presença de minerais ferrimagnéticos na fração areia, os quais não foram detectados pela técnica dipritometria de raios-X, por estarem em quantidades muito pequenas.

\section{Fração Silte}

O intervalo de comprimento de onda médio utilizado para avaliação da resposta espectral da fração silte foi de 1.060 a $1.900 \mathrm{~nm}$ para as amostras da usina Cooperval e de 1.090 a $1.890 \mathrm{~nm}$ para as amostras da FEI, considerando o horizonte de superfície e de subsuperficie. As equações de regressão obtidas para os experimentos são apresentadas no quadro 1.

Ao contrário do obtido nas frações argila e areia, a fração silte não apresentou comportamento espectral linear, e sim curvilíneo (hiperbólico), altamente significativo para quantificar sua relação com o fator de reflectância. Observou-se decréscimo brusco no fator de reflectância até a porção de $5 \mathrm{~g}$ (50\% de silte) nos dois horizontes e, a partir daí, decréscimo menos acentuado com tendência linear, ou seja, a energia eletromagnética absorvida não apresentou variação expressiva com o aumento na quantidade de silte.

Esse comportamento deve-se à presença de diversos componentes nas amostras (óxido de Fe, quartzo, rutilo, gibbsita), os quais atuam de forma diferente sobre o intervalo de comprimento de onda médio pesquisado. Portanto, os modelos de regressão que foram desenvolvidos apresentam diferentes naturezas sobretudo por causa desses fatores, concordando com Bhargava \& Mariam (1990).

Deve-se considerar ainda que o silte, por ser uma fração intermediária entre materiais bem
Usina_Cooperval_HAp
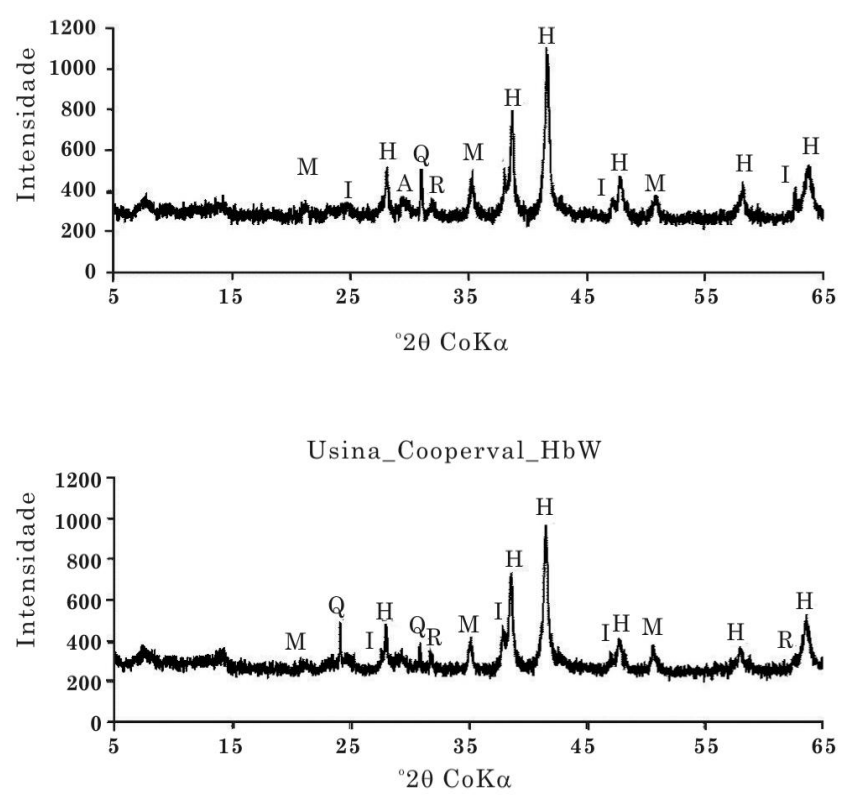

FEI_HAP
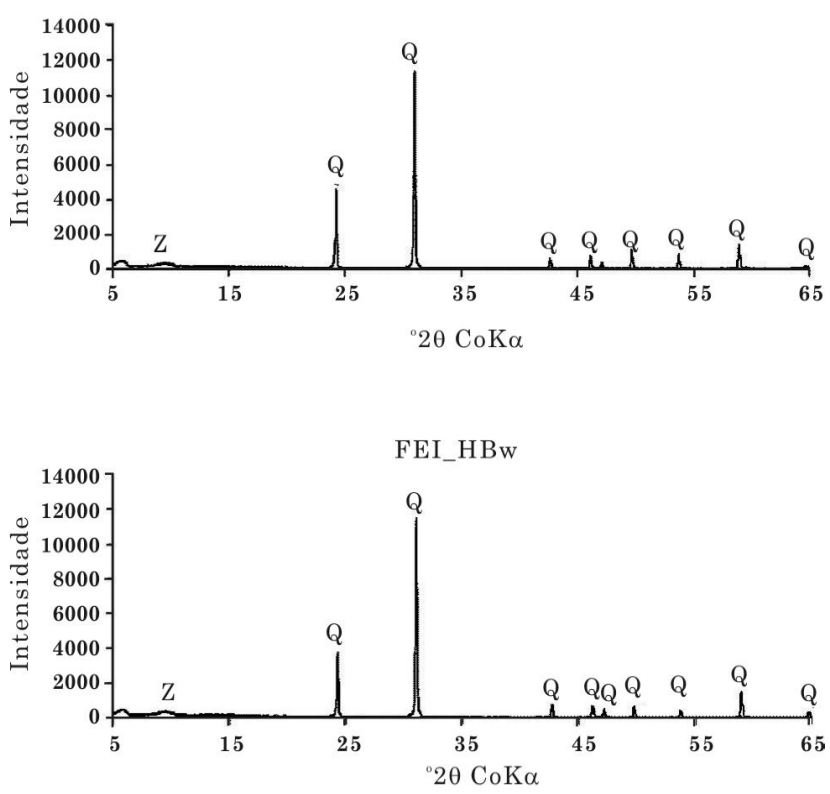

Figura 2. Difratograma de raios-X (montagem em pó) da fração areia pertencente aos horizontes Ap (HAp) e Bw (HBw). A: anatásio; H: hematita; I: ilmenita; R: rutilo; Q: quartzo; M: maghemita/magnetita. 
intemperizados e materiais de difícil intemperismo, possui diferentes componentes minerais, não sendo, portanto, uma fração com constituição bem definida. Dessa maneira, como o albedo depende das propriedades físicas, químicas e mineralógicas dos solos e o silte varia muito sua constituição, é natural que este tenha padrão espectral diferente do da argila e da areia, as quais são mais bem definidas e mais estáveis do ponto de vista mineralógico. Essas afirmações são corroboradas por meio dos difratogramas de raios-X, os quais são apresentados na figura 3.

Os resultados apresentados pelos difratogramas mostraram que a mineralogia da fração silte para o horizonte Ap foi semelhante nos dois Latossolos Vermelhos, independentemente do material de origem. A única exceção foi a maghemita/magnetita, que não foi constatada na amostra advinda da FEI. É possível observar que a caulinita, a hematita e o quartzo foram os minerais predominantes. No entanto, traços de minerais, como do anatásio, do rutilo e da gibbsita, também foram detectados. Por sua vez, os difratogramas do horizonte $\mathrm{Bw}$ apontaram para uma mistura entre minerais, em que o quartzo e a hematita são os dominantes na fração silte dos solos das duas áreas. Além destes, outros minerais, como caulinita, maghemita/magnetita, gibbsita e rutilo, foram encontrados, porém em menor proporção.

Esses dados corroboram as afirmações feitas anteriormente, mostrando a complexidade da mineralogia nesta fração, a qual possui ao mesmo tempo minerais provenientes de um forte intemperismo, típicos da fração argila, assim como minerais mais dificeis de serem intemperizados, típicos da fração areia, acarretando um padrão de fator de reflectância hiperbólico.

\section{Validação dos modelos}

Após obtenção dos modelos para cada fração individual (Quadro 1), o passo seguinte foi realizar a validação dos mesmos, a partir de amostras desconhecidas e no estado natural coletadas na área de Lobato. Os teores de silte, areia e argila obtidos pelos modelos foram confrontados com os obtidos em laboratório por meio do teste t para averiguar se as médias observadas eram iguais às estimadas. No quadro 2 são apresentados os resultados do teste t para os horizontes de superfície.

Os resultados mostraram que a areia estimada para as amostras de Lobato pelo modelo da usina Cooperval não se diferenciou da determinada em laboratório. Por outro lado, as frações silte e argila apresentaram diferenças significativas a $5 \%$, quando comparados os dois métodos. Nesse caso, atenção especial deve ser dada ao silte, em que as diferenças entre as médias foram elevadas, mostrando mais uma vez a dificuldade de estimar esse atributo a partir de sua resposta espectral.

$\mathrm{Na}$ avaliação dos resultados obtidos por meio dos modelos da FEI, constatou-se que as frações silte e argila das amostras de Lobato apresentaram diferenças significativas quando confrontados os valores determinados em laboratório com aqueles estimados pelos modelos. No entanto, as médias para a fração areia não puderam ser confrontadas, uma vez que o valor estimado ficou acima de $100 \%$. O que
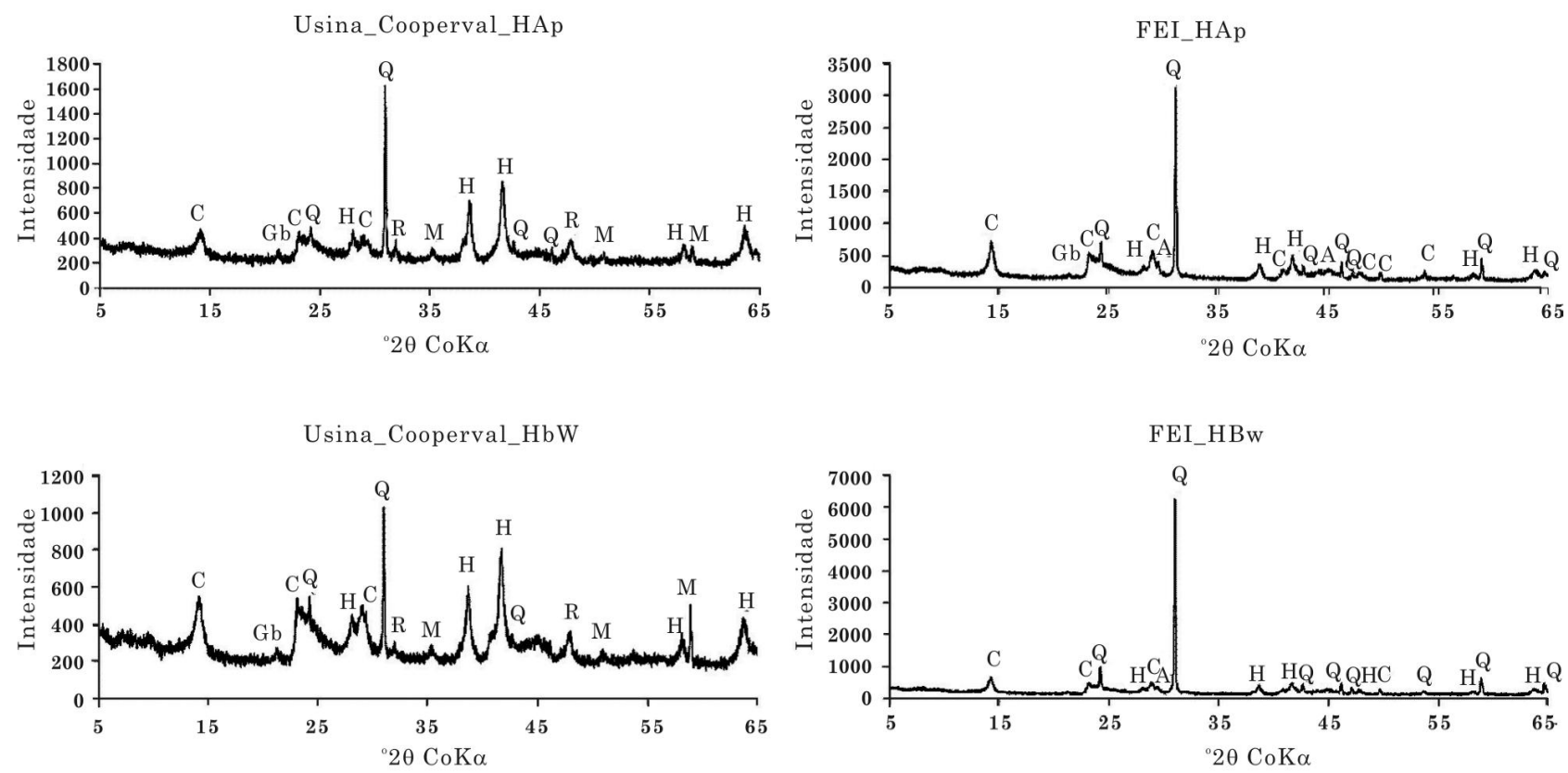

Figura 3. Difratograma de raios-X (montagem em pó) da fração silte pertencente aos horizontes Ap (HAp) e Bw (HBw). H: hematita; R: rutilo; Q: quartzo; M: maghemita/magnetita; C: caulinita; Gb: gibbsita; A: anatásio. 
se observa na maioria dos casos, neste estudo, é que houve superestimação durante a quantificação das frações, fato esse que pode estar ligado à matéria orgânica (MO), uma vez que as frações utilizadas nos tratamentos não apresentavam quantidades significativas de MO, já que esta havia sido removida durante $\mathrm{o}$ fracionamento.

Dessa forma, os fatores de reflectância das frações utilizadas como variáveis independentes não sofreram interferência da MO, apresentando, portanto, valores elevados. Por outro lado, as amostras de solo de Lobato que foram utilizadas para validar os modelos apresentaram quantidades variáveis de $\mathrm{MO}$, a qual influencia o fator de reflectância dos solos (Dalmolin et al., 2005). Assim, quando as reflectâncias dessas amostras foram inseridas nos modelos como variável dependente (y), seus baixos valores prejudicaram a estimação da variável independente (x), a qual foi representada pelos atributos.

Além do fator discutido anteriormente, outro que pode ter influenciado os resultados diz respeito à interação energia-matéria. Segundo Moreira (2005), a reflectância é uma propriedade cumulativa que depende da combinação de seus componentes, ou seja, a quantidade de energia refletida pelo solo é função de todos os fatores que se encontram juntos nesse solo. Como os modelos de regressão foram gerados a partir de atributos individuais e testados com amostras naturais, pode ser que os modelos não tenham sido capazes de expressar de forma satisfatória o efeito dessas combinações.

Procedimento semelhante foi realizado com os modelos obtidos para o horizonte subsuperficial. Os resultados encontram-se no quadro 2.

Resultados semelhantes aos obtidos para os modelos dos horizontes de superfície foram observados ao se avaliarem os modelos dos horizontes subsuperficiais. Nessa etapa, todas as médias mostraram diferenças significativas a $5 \%$, quando comparados os valores observados com os estimados. Verificou-se a mesma tendência para as frações silte, areia e argila das duas áreas, sendo a fração silte a que apresentou a maior diferença.

Por outro lado, embora a fração areia das amostras de solo da usina Cooperval tenha apresentado diferença significativa quando comparada os resultados estimados por meio de seus modelos com aqueles de laboratório, observou-se que as médias foram relativamente próximas. Contrariamente, o modelo ajustado para a fração areia da FEI não foi capaz de estimar a quantidade de areia nas amostras naturais de Lobato, provavelmente em razão de problemas já discutidos.

O resultado superior obtido para a fração areia em ambos os horizontes, provavelmente, ocorreu em função de sua melhor representatividade dentro de uma amostra de solo, ou seja, embora a MO e os óxidos de $\mathrm{Fe}$ sejam variáveis capazes de interferir na estimativa dos atributos do solo, a areia apresenta características espectrais que lhe permitem superar o efeito desses elementos, concordando com o descrito por Resende et al. (2005).

\section{CONCLUSÕES}

1. Foi possível estimar a percentagem de areia nas amostras de solo de Lobato de maneira satisfatória quando utilizados os modelos individuais da usina Cooperval ajustados para esse atributo, não sendo obtido o mesmo quando da utilização dos modelos

Quadro 2. Resultados do teste t obtidos entre os valores determinados em laboratório e estimados pelas equações, para os horizontes Ap e Bw, utilizando dados da área de Lobato

\begin{tabular}{|c|c|c|c|c|c|c|}
\hline \multirow{2}{*}{$\begin{array}{l}\text { Valor do } \\
\text { atributo }\end{array}$} & \multicolumn{3}{|c|}{ Usina Cooperval } & \multicolumn{3}{|c|}{ FEI } \\
\hline & Areia & Silte & Argila & Areia & Silte & Argila \\
\hline \multirow{4}{*}{$\begin{array}{l}\text { Observado }^{1} \\
\text { Estimado }^{2}\end{array}$} & \multicolumn{6}{|c|}{ Horizonte Ap } \\
\hline & $66,70 \mathrm{a}$ & $3,80 \mathrm{a}$ & $29,50 \mathrm{a}$ & $66,70 \mathrm{a}$ & $3,80 \mathrm{a}$ & $29,50 \mathrm{a}$ \\
\hline & 67,70 a & $45,60 \mathrm{~b}$ & $74,12 \mathrm{~b}$ & - & $82,80 \mathrm{~b}$ & $78,38 \mathrm{~b}$ \\
\hline & \multicolumn{6}{|c|}{ Horizonte Bw } \\
\hline Observado $^{1}$ & $58,50 \mathrm{a}$ & $3,02 \mathrm{a}$ & $38,48 \mathrm{a}$ & $58,50 \mathrm{a}$ & $3,02 \mathrm{a}$ & 38,48 a \\
\hline Estimado $^{2}$ & $63,40 \mathrm{~b}$ & $59,37 \mathrm{~b}$ & $68,98 \mathrm{~b}$ & - & $76,84 \mathrm{~b}$ & $80,31 \mathrm{~b}$ \\
\hline
\end{tabular}

(1) Valor médio dos atributos determinados em laboratório; ${ }^{(2)}$ Valor médio dos atributos determinados pelas equações de regressão; médias seguidas por letras diferentes nas colunas diferenciam-se pelo teste $\mathrm{t}$ a $5 \%$. 
individuais ajustados para a Fazenda Experimental de Iguatemi.

2. Não foi possível estimar a percentagem de silte e argila nas amostras de solo de Lobato satisfatoriamente quando utilizados modelos individuais desses atributos ajustados para a usina Cooperval e para a Fazenda Experimental de Iguatemi.

3. Embora os resultados alcançados não tenham atingido o patamar ideal, a espectrorradiometria difusa mostrou ser uma ferramenta promissora na estimativa dos atributos físicos do solo, podendo num futuro próximo auxiliar ou mesmo substituir os métodos analíticos de laboratório, reduzindo assim o tempo e o custo das análises.

\section{AGRADECIMENTO}

Ao Conselho Nacional de Desenvolvimento Científico e Tecnológico (CNPq), pela concessão de bolsa de Doutorado ao primeiro autor (processo $\mathrm{n}^{\circ}$ 141874/2009-0).

\section{LITERATURA CITADA}

BHARGAVA, D.S. \& MARIAM, D.W. Spectral reflectance relationship to turbidity generated by different Clay materials. Photog. Eng. Rem. Sens., 56:225-229, 1990.

DALMOLIN, R.S.D.; GONÇALVES, C.N.; KLAMT, E. \& DICK, D.P. Relação entre os constituintes do solo e seu comportamento espectral. Ci. Rural, 35:481-489, 2005.

DEMATTÊ, J.A.M. \& GARCIA, G.J. Avaliação de atributos de Latossolo Bruno e de terra Bruna Estruturada na região de Guarapuava, Paraná, por meio de sua energia refletida. R. Bras. Ci. Solo, 23:343-355, 1999.

EMPRESA BRASILEIRA DE PESQUISA AGROPECUÁRIA EMBRAPA. Manual de métodos de análises de solo. 2.ed. Rio de Janeiro, 1997. 212p.

EMPRESA BRASILEIRA DE PESQUISA AGROPECUÁRIA EMBRAPA. Sistema brasileiro de classificação de solos. 2.ed. Brasília, 2006. 412p.

INTERNATIONAL CENTRE FOR DIFRACTION DATA - ICDD. Software: X'Pert HighScore Plus, 2004. Banco de dados: 1996.
LEE, K.S.; SUDDUTH, K.A.; DRUMMOND, T.S.; LEE, D.H.; KITCHEN, N.R. \& CHUNG, S.O. Calibration methods for soil property estimation using reflectance spectroscopy. ASABE, 53:675-684, 2010.

MOREIRA, M.A. Fundamentos do sensoriamento remoto e metodologias de aplicação. 3.ed. atualizada e ampliada. Viçosa, MG, Universidade Federal de Viçosa, 2005. $320 \mathrm{p}$.

NANNI, M.R. Dados radiométricos obtidos em laboratório e no nível orbital na caracterização e mapeamento de solos. Piracicaba, Escola superior de Agricultura Luiz de Queiroz, 2000. 366p. (Tese de Doutorado).

NANNI, M.R. \& DEMATTÊ, J.A.M. Spectral reflectance methodology in comparison to traditional soil analysis. Soil Sci. Soc. Am. J., 70:393-407, 2006.

RENCZ, A.N. Remote sensing for the earth sciences: Manual of remote sensing. 3.ed. New York, John Wiley \& Sons, 1999. 699p.

RESENDE, M.; CURI, N.; KER, J.C. \& REZENDE, S.B. Mineralogia de solos brasileiros: Interpretação e aplicações. Lavras, Universidade Federal de Lavras, 2005. 192p.

SAS - Institute. SAS, software: user's guide. version 8.2. Cary, 2001.

SILVA, A.R.; SOUZA JUNIOR, I.G. \& COSTA, A.C.S. Susceptibilidade magnética do horizonte B de solos do estado do Paraná. R. Bras. Ci. Solo, 34:329-337, 2010.

SORENSEN, L.K. \& DAALSGARD, S. Determination of clay and other soil properties by Near Infrared Spectroscopy. Soil Sci. Soc. Am. J, 69:159-167, 2005.

SOUSA JÚNIOR, J.G.; DEMATTÊ, J.A.M. \& ARAÚJO, S.R. Modelos espectrais terrestres e orbitais na determinação de teores de atributos dos solos: Potencial e custos. Bragantia, 70:610-621, 2011.

SHEPHERD, K.D. \& WALSH, M.G. Development of reflectance spectral libraries for characterization of soil properties. Soil Sci. Soc. Am. J., 66:988-998, 2002.

VISCARRA ROSSEL, R.A.; CATTLE, S.R.; ORTEGA, A. \& FOUAD, Y. In situ measurements of soil colour, mineral composition and clay content by vis-NIR spectroscopy. Geoderma, 150:253-266, 2009.

VOLKAN BILGILI, A.; van ES, H.M.; AKBAS, F.; DURAK, A. \& HIVELY, W.D. Visible-near infrared reflectance spectroscopy for assessment of soil properties in a semiarid area of Turkey. J. Arid Environ., 74:229-238, 2010. 
R. Bras. Ci. Solo, 36:1157-1165 